\title{
Occurrence of various types of penicillinase plasmid among 'hospital' staphylococci
}

\author{
K. G. H. DYKE ${ }^{1}$ AND M. H. RICHMOND \\ From the Cross-Infection Reference Laboratory, Central Public Health Laboratory, Colindale Avenue, London, \\ and the Department of Molecular Biology, University of Edinburgh
}

SYNOPSIS The type of penicillinase plasmid carried by penicillin-resistant cultures of Staphylococcus aureus isolated from eight London hospitals has been determined.

Among 'endemic' hospital staphylococci, cultures resistant to mercury salts and producing large amounts of A-type penicillinase, a high proportion of which is extracellular, are most common. C-type penicillinase is rarely associated with resistance to mercury salts.

The majority of strains resistant to penicillin and at least one other antibiotic carried the $\alpha$ plasmid.

Possible reasons for the prevalence of the $\alpha$-plasmid among endemic hospital staphylococci are discussed.

In most strains of Staphylococcus aureus the genes which determine the synthesis of penicillinase are carried on an extrachromosomal particle or plasmid (Novick, 1963; Richmond, 1965a). Three naturally occurring varieties of the staphylococcal penicillinase molecule can be distinguished by their reaction with a specific anti-penicillinase serum (Richmond, 1965b) and the penicillinase plasmids of Staph. aureus have been classified into three main groups on this basis (Novick and Richmond, 1965; Richmond, 1965a). Further types of plasmid can be recognized by the presence in the same plasmid of other genetic markers. A total of 10 plasmid types (Table I) has been identified, using as criteria the presence or absence of erythromycin resistance (Novick and Richmond, 1965), resistance to mercuric chloride (Richmond and John, 1964), and the proportion of the penicillinase which is liberated into the medium during the exponential growth (Richmond, 1965a). The type of penicillinase plasmid carried by staphylococcal strains may have some bearing on their distribution in nature. Most strains able to persist in the hospital environment (the so-called 'hospital' staphylococci) synthesize large amounts of penicillinase, and are resistant to mercuric chloride and to at least one antibiotic other than penicillin (Richmond, Parker, Jevons, and John, 1964). We decided, therefore, to examine a collection of strains of Staph.

1Seconded from Department of Microbiology, National Institute for Medical Research, The Ridgeway, Mill Hill, London, N.W.7.

Received for publication 26 July 1966. aureus isolated from hospital patients and to try to assess the relevance of the plasmid type to the ability to survive in the hospital.

The immunological B-type of penicillinase (carried by plasmid $\delta$ ) seems to be confined to staphylococci of phage group II (Richmond, 1965b). Although these strains frequently cause sporadic infection in the general population, they rarely spread in hospitals. We therefore confined our attention in the present investigation to the producers of A-type and C-type penicillinase.

\section{METHODS AND MATERIALS}

STRAINS Each year, eight hospitals in the London area submit approximately 100 cultures of Staphylococcus aureus consecutively isolated from septic lesions to the Cross-Infection Reference Laboratory. Those strains, which are represented three or more times within 100 cultures submitted in this way, are considered to be 'endemic', but those which occur only once are said to be 'sporadic'. These criteria give a more reliable identification of 'endemic' than of 'sporadic' strains since, for example, the single appearance of a strain towards the end of a series of 100 cultures might be the first example of a strain subsequently to become 'endemic'.

For the present investigation, only those strains isolated during 1963 which were lysed by at least one of the phages of groups I or III and which were resistant to penicillin are considered. Within these limits, one representative of each endemic strain from each of the eight hospitals, and a culture of every sporadic strain from four of the hospitals, were studied. 
Two further cultures will be discussed, since they carry rare types of penicillinase plasmid. They are strain 258 (Hashimoto, Kono, and Mitsuhashi, 1964; Novick and Richmond, 1965; Richmond, 1965a), which carries the $\gamma$-plasmid; and strain 147 (Segalove, 1947; Richmond, $1965 \mathrm{a}$ and b), which carries the $\beta$-plasmid. Strain 258 was obtained from a lesion recently, but strain 147 was isolated from a food poisoning outbreak at Nashville in the United States in 1933, long before penicillin was used therapeutically (Segalove, 1947). Neither of them is included in the Tables.

PENICILlinase estimations The estimations were of quantity, degree of extracellularity, and immunological type.

Quantity Penicillinase activity was measured by the iodometric method of Perret (1954), as modified by Novick (1962). One penicillinase unit $=1 \cdot 0 \mu$ mole benzylpenicillin destroyed per hour at $30^{\circ} \mathrm{C}$. and $p \mathrm{H} \mathrm{5.9}$. The amount of penicillinase (enzyme units/mg. dry weight bacteria) was determined after induction under standard conditions, as described previously (Richmond et al., 1964). A stock strain (524SC) was induced under the same conditions in each experiment to check the variability of induction from day to day. The quantitiy of enzyme synthesized by the test strain is sometimes quoted as a factor (F) calculated as follows (see Richmond et al., 1964):

specific enzyme activity of test strain (units/mg. dry $F=\frac{\text { wt. organism) }}{\text { specific enzyme activity of strain 524SC (units/mg. }}$

The average penicillinase content of a culture of strain 524SC, induced under standard conditions, was 240 units/mg. dry wt. bacteria over the course of these experiments.

Degree of extracellularity A portion of a fullyinduced culture was centrifuged as $2,500 \mathrm{~g}$ for $10 \mathrm{~min}$. and the amount of penicillinase in the supernatant was estimated. The amount of extracellular penicillinase was expressed as a percentage of the activity of the whole culture, which had been determined separately.

Immunological type A portion (about $5.0 \mathrm{ml}$.) of a fully-induced culture was centrifuged at $2,500 \mathrm{~g}$ for 10 min. and the amount of enzyme activity in the supernatant estimated. This supernatant was diluted in fresh CY medium if necessary, and a portion containing 20 units enzyme (in 0.2 to $1.0 \mathrm{ml}$.) was placed in each of two flasks. Similar amounts of purified A-type penicillinase in a second pair of flasks acted as standard. Sufficient antiexopenicillinase to give a full stimulation (see Richmond,
$1963,1965 \mathrm{~b}$ for details of this phenomenon) was placed in one of the standard and one of the test flasks, the other pair of flasks acting as controls. All four flasks were incubated at room temperature for 10 minutes to allow the enzyme-antiserum reaction to be completed, and the enzyme activity in each flask was assayed as described previously (Richmond, 1963). A large increase in enzyme activity (usually to about 80 units) in the presence of antiserum is characteristic of A-type penicillinase; the enzyme activity of C-type enzyme is not stimulated by anti-A-type exopenicillinase serum, but B-type enzyme is stimulated a maximum of one and a half times (Richmond 1965b).

CHARACTERIZATION OF STRAINS Phage typing was carried out by the method of Blair and Williams (1961). Antibiotic resistance patterns were determined with an Oxoid Multodisc containing the following quantities of antibiotics: benzylpenicillin, 1.5 units; streptomycin, $10 \mu \mathrm{g}$.; chloramphenicol, $10 \mu \mathrm{g}$.; tetracycline, $10 \mu \mathrm{g}$.; erythromycin, $10 \mu \mathrm{g}$.; novobiocin, $5 \mu \mathrm{g}$. Mercury resistance (Moore, 1960) was investigated by the disc method of Green (1962).

\section{RESULTS}

PLASMID TYPES Table I shows the types of penicillinase plasmid found so far in Staphylococcus aureus and the characters by which they are recognized. The distinction between plasmids $\alpha$ and $\theta, \beta$ and $\eta, \epsilon$ and $\iota$, and $\zeta$ and $\kappa$, is based entirely on the proportion of the penicillinase released into the culture medium under standard conditions of induction. Although the 'degree of extracellularity' is co-transducible with penicillinase and therefore plasmid-borne (Richmond, 1965a), the wide range of values found (from $5 \%$ to $60 \%$ ) makes it difficult to use this parameter. When the extracellularity of the enzyme is high (30 to $60 \%$ ) or low ( 5 to $10 \%$ ) there is no difficulty, but some strains with intermediate values are isolated. In the classification used here, an arbitrary value of $25 \%$ is used as a boundary between 'high' and 'low' extracellularity.

ENZYME PRODUCTION AND PLASMID TYPE Table II shows the distribution of plasmid types among the 96 cultures examined. The results are set out in two ways: first for single plasmids and then grouped so as to neglect the character of 'extracellularity'. All but one of the cultures belonged to one of five

\section{TABLE I}

CHARACTERISTICS OF THE TYPES OF PENICILLINASE PLASMID IDENTIFIED TO DATE IN PENICILLIN-RESISTANT Staphylococcus aureus CULTURES

Plasmid type
Penicillinase type
Erythromycin resistance
Mercury resistance
Extracellularity (\%)

$\begin{array}{ll}\boldsymbol{\alpha} & \boldsymbol{\beta} \\ \mathbf{A} & \mathbf{C} \\ \overline{+} & - \\ >25 & +\end{array}$

$\gamma \quad \delta \quad \varepsilon$

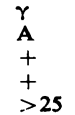

8
B
-
$>25$ $\zeta$
$\overline{-}$
$>25$

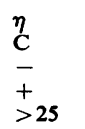

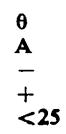


TABLE II

DISTRIBUTION OF PLASMID TYPES IN THE PRESENT SURVEY AND THE ASSOCIATION BETWEEN PLASMID TYPE AND QUANTITY OF PENICILLINASE FORMED

\begin{tabular}{|c|c|c|c|c|c|c|c|c|c|c|c|c|c|c|c|}
\hline & \multirow{2}{*}{$\begin{array}{l}\text { No. of } \\
\text { Strains }\end{array}$} & \multicolumn{10}{|c|}{ Plasmid Type } & \multicolumn{4}{|c|}{ Plasmids Grouped in Pairs } \\
\hline & & $\alpha$ & $\beta$ & $\gamma$ & $\delta$ & $\varepsilon$ & $\zeta$ & $\eta$ & $\theta$ & $\iota$ & $\kappa$ & $\alpha / \theta$ & $\beta / \eta$ & $\varepsilon / 6$ & $\zeta / \kappa$ \\
\hline $\begin{array}{l}\text { Total } \\
F=>0.6 \\
F=<0.6\end{array}$ & $\begin{array}{l}96 \\
45 \\
51\end{array}$ & $\begin{array}{r}36 \\
28 \\
8\end{array}$ & $\begin{array}{l}\mathbf{0} \\
\mathbf{0} \\
\mathbf{0}\end{array}$ & $\begin{array}{l}0 \\
0 \\
0\end{array}$ & $\begin{array}{l}0 \\
0 \\
0\end{array}$ & $\begin{array}{r}14 \\
4 \\
10\end{array}$ & $\begin{array}{l}29 \\
11 \\
18\end{array}$ & $\begin{array}{l}1 \\
1 \\
0\end{array}$ & $\begin{array}{l}\mathbf{0} \\
\mathbf{0} \\
\mathbf{0}\end{array}$ & $\begin{array}{r}11 \\
1 \\
10\end{array}$ & $\begin{array}{l}5 \\
0 \\
5\end{array}$ & $\begin{array}{r}36 \\
28 \\
8\end{array}$ & $\begin{array}{l}1 \\
1 \\
0\end{array}$ & $\begin{array}{r}25 \\
5 \\
20\end{array}$ & $\begin{array}{l}34 \\
11 \\
23\end{array}$ \\
\hline
\end{tabular}

'Plasmids paired by neglecting the 'degree of extracellularity' character.

$F=\frac{\text { Specific enzyme activity (units/mg. dry wt. organisms) for test strain }}{\text { Specific enzyme activity (units/mg. dry wt. organisms) for strain 524SC }}$

plasmid types ( $\alpha, \epsilon, \zeta, \iota$, and $\kappa$ ). The most common $(\alpha)$ consisted of organisms which formed A-type penicillinase with a 'high' degree of extracellularity, and were mercury-resistant. The next most common $(\zeta)$ formed C-type penicillinase, also mainly extracellularly, but were mercury-sensitive. Mercury resistance was commonly associated with the formation of A-type penicillinase (types $\alpha, \epsilon$, and $\iota ; 36$ out of 61 cultures) and was rare among those which formed C-type penicillinase (types $\zeta, \kappa$, and $\eta$; one out of 35 cultures). All the mercury-resistant cultures (types $\alpha$ and $\eta$ ) had more than $25 \%$ of the enzyme extracellular, and all but one of them formed A-type penicillinase (type $\alpha$ ).

Examination of the total amount of penicillinase synthesized by members of the different plasmid types again singles out the $\alpha$-plasmid (see Table II). It is only in this plasmid that the strains making large amounts of penicillinase $(F>0.6)$ outnumber those making smaller amounts; but among the mercury sensitive strains, whether they synthesize Aor C-type penicillinase, there is also a tendency for the production of large amounts of penicillinase to be more often associated with 'high' extracellularity (types $\epsilon$ and $\zeta$ ) than with 'low' extracellularity (types ८ and $\kappa)$.

ANTIBIOTIC RESISTANCE AND PLASMID TYPE AMONG 'ENDEMIC' AND 'SPORADIC' STRAINS Table III shows the 96 test cultures classified according to their anti- biotic resistance patterns and whether they are 'endemic' or 'sporadic' strains. Again the $\alpha$-plasmid is conspicuous, since 26 of 37 endemic strains carried this plasmid, as did $\mathbf{3 5}$ of $\mathbf{4 3}$ multiple-resistant and $\mathbf{3 0}$ of 38 tetracycline-resistant strains. In this series, 10 of 36 strains carrying the $\alpha$-plasmid were classified as 'sporadic'. However, nine out of 10 of them were resistant to at least one antibiotic other than penicillin, while seven of them had clearly similar phage patterns to 'endemic' strains carrying the $\alpha$-plasmid isolated in other hospitals. This suggests that at least seven of these 10 strains did not differ materially from the ones that had been classified as 'endemic' in this series.

It is clear, therefore, that strains carrying the $\alpha$-plasmid are by far the most common among 'hospital' staphylococci. All the other 'endemic' strains (11 of 36) carried either one of the $\epsilon / \iota$ or $\zeta / \kappa$ pairs of plasmids; that is, they were mercurysensitive and synthesized either A-type $(\epsilon / \iota)$ or C-type $(\zeta / \kappa)$ penicillinase. Of these 11 strains, eight were multiple resistant and 10 liberated more than $25 \%$ of their penicillinase into the growth medium; in these respects, therefore, they were similar to strains carrying an $\alpha$-plasmid. Only one strain carrying a plasmid of the $\beta / \eta$ pair (C-type, resistant to mercury) was isolated among the 96 test strains in this series.

'RARE' PLASMIDS Apart from the $\delta$-plasmid, which is confined to strains of phage-group II, three others

TABLE III

THE ASSOCIATION BETWEEN PLASMID TYPE AND ANTIBIOTIC RESISTANCE PATTERNS AMONG 'ENDEMIC' AND 'SPORADIC' STAPHYLOCOCCI ISOLATED IN HOSPITALS

\begin{tabular}{|c|c|c|c|c|c|c|c|c|c|c|c|c|c|c|c|}
\hline & \multirow{2}{*}{$\begin{array}{l}\text { No. of } \\
\text { Strains }\end{array}$} & \multicolumn{10}{|c|}{ Plasmid Types } & \multicolumn{4}{|c|}{ Plasmids Grouped in Pairs } \\
\hline & & $\alpha$ & $\beta$ & $\boldsymbol{\gamma}$ & $\delta$ & $\varepsilon$ & $\zeta$ & $\eta$ & $\theta$ & $i$ & $\kappa$ & $\alpha / \theta$ & $\beta / \eta$ & $\varepsilon / \iota$ & $\zeta / \kappa$ \\
\hline Total & 96 & 36 & $\mathbf{0}$ & 0 & 0 & 14 & 29 & 1 & 0 & 11 & 5 & 36 & 1 & 25 & 34 \\
\hline 'Endemic' & 37 & 26 & 0 & 0 & $\mathbf{0}$ & 5 & 5 & $\mathbf{0}$ & 0 & 1 & 0 & 26 & 0 & 6 & 5 \\
\hline 'Sporadic' & 59 & 10 & 0 & 0 & $\mathbf{0}$ & 9 & 24 & 1 & 0 & 10 & 5 & 10 & 1 & 19 & 29 \\
\hline Multiple resistant & 43 & 35 & 0 & 0 & 0 & 2 & 3 & 0 & 0 & 3 & 0 & 35 & 0 & 5 & 3 \\
\hline Resistant only to penicillin & 53 & 1 & $\mathbf{0}$ & $\mathbf{0}$ & $\mathbf{0}$ & 12 & 26 & 1 & 0 & 8 & 5 & 1 & 1 & 20 & 31 \\
\hline Resistant to tetracycline & 38 & 30 & 0 & 0 & $\mathbf{0}$ & 2 & 3 & 0 & $\mathbf{0}$ & 3 & $\mathbf{0}$ & 30 & 0 & 5 & 3 \\
\hline
\end{tabular}

'Plasmids paired by neglecting the 'extracellularity' character. 
$(\beta, \gamma$, and $\theta)$ were absent from the cultures examined in this survey.

The $\beta$-plasmid (see Table I) is carried by strain 147, which was isolated in 1933, and no other strain has yet been shown to carry it. Under standard conditions of induction the strain liberates less than $10 \%$ of its enzyme into the growth medium, and on these grounds the plasmid probably differs from the $\eta$-plasmid which was present once among the 96 test strains (see above). Whether or not the difference in the degree of extracellularity of the enzyme is sufficient to distinguish these two plasmids, the presence on a plasmid of the A-type penicillinase without an associated mercury resistance marker is clearly uncommon.

The second type of 'rare' plasmid is the $\gamma$-plasmid present in strain 258 (Hashimoto et al., 1964). In addition to the penicillinase and mercury resistance genes, this plasmid also carries genes conferring erythromycin resistance.

Strains, resistant to mercury, producing A-type penicillinase with low extracellularity, i.e., with the $\theta$ plasmid, were absent from this survey, although they do exist (Richmond, unpublished observation).

\section{DISCUSSION}

Although the penicillinase gene of Staph. aureus may occasionally be carried on the chromosome (Asheshov, 1966), our investigations indicate that this occurs rarely, and there is reason to believe that, in all or practically all of the cultures included in this series, it formed part of the plasmid.

The frequency with which the $\alpha$-plasmid is found in this series of staphylococci suggests that it may be associated with the ability of the staphylozoccal strain carrying it to persist in the hospital environment and to cause lesions in those it infects. Among the characters known to be carried by the $\alpha$-plasmid, penicillinase production may be important in this connexion, but there is no reason to believe that the A-type penicillinase (characteristic of the $\alpha$-plasmid) is any more effective at destroying penicillin than the C-type enzyme (Richmond, 1965b). Indeed, the presence of the $\zeta$-plasmid in some of the endemic strains is in accordance with the laboratory observation that the C-type enzyme is no less efficient than the A-type at hydrolysing penicillin under physiological conditions. Nor can 'mercury resistance' (whatever this may imply in terms of the physiology of the cells) be of outstanding importance, since 12 of 31 endemic strains in this series are mercurysensitive. One possibility is that some other unidentified character is present on the $\alpha$-plasmid, and perhaps on certain of the $\epsilon$ - and $\zeta$-plasmids. This character could have one of many effects. For example, it could be involved in the ability of the organism to cause septic lesions. Alternatively it might be one that allowed (or the absence of one that did not allow) the uptake into the cell of a second plasmid carrying tetracycline resistance. Resistance to tetracycline probably confers an important selective advantage upon staphylococci in British hospitals at the present time. Any strain carrying a penicillinase plasmid which blocked the uptake of another plasmid carrying tetracycline resistance would stand little chance of establishing itself in a hospital. The blocking by one phage of the sensitivity of an organism to a related phage suggests that a similar phenomenon could occur among plasmids, but preliminary experiments indicate that in four strains carrying the $\epsilon$-plasmids the frequency of transduction of tetracycline resistance into the strain is the same for the penicillinase-producing strain as for its derived penicillinase-negative variant. It seems unlikely that any characters yet identified on the $\alpha$-plasmid are the direct cause of the prevalence of this plasmid among 'hospital' staphylococci.

The absence of the $\beta$-plasmid from the test series suggests that it is now less common among staphylococci than formerly. It was found in one out of 11 penicillinase-producing cultures that had been isolated before 1940 , and has not been found since. Even the $\eta$-plasmid, which differs from the $\beta$-plasmid only in the degree of extracellularity of the enzyme, was present in one strain out of the 96 examined in this series. The possibility that the $\beta$ - and $\eta$-plasmids might be characteristic of food poisoning strains, and thus not common in the 96 strains selected for this survey, seems unlikely from the results obtained in a limited survey of 12 independent food poisoning strains isolated in Britain (Dyke, unpublished experiments).

The rarity of the $\gamma$-plasmid, in which the penicillinase, mercury, and erythromycin genes are closely linked, may be attributed to some other factor. Perhaps this is a 'young' plasmid whose distribution will become more widespread as time goes on. Certainly the prevalence of plasmids carrying several closely linked antibiotic resistance markers in the Enterobacteria ( $R$ factors) suggests it may be an advantage to an organism to have all its resistance markers together on a single extra-chromosomal piece of desoxyribonucleic acid (Datta, 1965). However, the linkage of the genes for penicillinase production and erythromycin resistance is exceptional among erythromycin-resistant staphylococci isolated in this country (Dyke and Richmond, unpublished experiments).

We wish to thank Drs. M. T. Parker and M. P. Jevons for their help in selecting strains for this survey and for their 
continuing advice and interest in the work. We also wish to thank Dr. W. Brumfitt, Professor A. C. Cunliffe, Dr. R. J. Evans, Dr. J. M. Fullerton, Dr. J. R. E. Richardson, Dr. K. E. Saunders, Professor R. A. Shooter, and Professor R. E. O. Williams for sending us the staphylococcal cultures which formed the basis of this investigation. Mr. D. J. McGillicuddy and Mrs. A. J. Raine gave expert technical assistance. We are indebted to Beecham Research Laboratories for a generous gift of methicillın.

REFERENCES

Asheshov, E. H. (1966). Nature (Lond.), 210, 804.
Blair, J. E., and Williams, R. E. O. (1961). Bull. Wld Hlth Org., 24, 771.

Datta, N. (1965). Brit. med. Bull., 21, 254.

Green, S. M. (1962). J. clin. Path., 15, 249.

Hashimoto, H., Kono, K., and Mitsuhashi, S. (1964). J. Bact., 88, 261.

Moore, B. (1960). Lancet, 2, 453.

Novick, R. P. (1962). Biochem. J., 83, 229.

- (1963). J. gen. Microbiol., 33, 121.

$\longrightarrow$, and Richmond, M. H. (1965). J. Bact., 90, 467.

Perret, C. J. (1954). Nature (Lond.), 174, 1012.

Richmond, M. H. (1963). Biochem. J., 88, 452.

- (1965a). Brit. med. Bull., 21, 260.

- (1965b). Biochem. J., 94, 584.

- and John, M. (1964). Nature (Lond.), 202, 1360.

-, Parker, M. T., Jevons, M. P., and John, M. (1964). Lancet, 1, 293.

Segalove, M. (1947). J. infect. Dis., 81, 228.

\section{Reports and Bulletins prepared by the Association of Clinical Biochemists}

The following reports and bulletins are published by the Association of Clinical Biochemists. They may be obtained from Mr. J. T. Ireland, Biochemistry Laboratory, Alder Hey Children's Hospital, Liverpool, 12. The prices include postage, but airmail will be charged extra.

\section{SCIENTIFIC REPORTS}

1 Colorimeters with Flow Through Cells. A Critical Assessment of 4 Instruments. 1965. P. M. G. BROUGHTON and C. RILEY. 13s $6 \mathrm{~d}$.

2 Colorimeters: A critical assessment of 5 commercial instruments. 1966. P. M. G. BROUGHTON, C. RILEY, J. G. H. COOK, P. G. SANDERS and H. BRAUNSBERG. $15 \mathrm{~s}$.

\section{TECHNICAL BULLETINS}

2 A Report on the Enzyme Questionnaire Circulated by the Scientific Committee. December 1964. A. H. GOWENLOCK. 1s.

3 Non-recording Spectrophotometers for the Visible and Ultraviolet Ranges. A comparative table of instruments available in Great Britain. May 1965. A. H.
GOWENLOCK, P. C. NICHOLAS, and J. H. WILKINSON. 1s. 6 d.

4 Control Solutions for Clinical Biochemistry. June 1965. P. M. G. BROUGHTON and A. H. GOWENLOCK. 1s. 6 d.

5 Recording Spectrophotometers. A comparative list of low-priced instruments readily available in Britain. July 1965 . P. SEWELL. 2s. 6 d.

6 A Guide to Automatic Pipettes. A list of more than 100 instruments compiled from manufacturers' literature. August 1965. P. M. G. BROUGHTON. 5s.

7 Variability Between AutoAnalyzer Modules. August 1965. B. E. NORTHAM. 1s. 6 d.

8 Flame Photometers. A comparative list of 15 instruments readily available in Britain. June 1966. C. RILEY. 4s. 